University of Nebraska - Lincoln

DigitalCommons@University of Nebraska - Lincoln

Agronomy \& Horticulture -- Faculty Publications

Agronomy and Horticulture Department

1996

\title{
Analysis of Aerial Photography for Nitrogen Stress within Corn Fields
}

Tracy M. Blackmer

USDA-ARS

James S. Schepers

University of Nebraska-Lincoln, james.schepers@gmail.com

Gary E. Varvel

University of Nebraska-Lincoln, gevarvel@windstream.net

George Meyer

University of Nebraska-Lincoln, gmeyer1@unl.edu

Follow this and additional works at: https://digitalcommons.unl.edu/agronomyfacpub

Part of the Plant Sciences Commons

Blackmer, Tracy M.; Schepers, James S.; Varvel, Gary E.; and Meyer, George, "Analysis of Aerial Photography for Nitrogen Stress within Corn Fields" (1996). Agronomy \& Horticulture -- Faculty Publications. 322.

https://digitalcommons.unl.edu/agronomyfacpub/322

This Article is brought to you for free and open access by the Agronomy and Horticulture Department at DigitalCommons@University of Nebraska - Lincoln. It has been accepted for inclusion in Agronomy \& Horticulture -Faculty Publications by an authorized administrator of DigitalCommons@University of Nebraska - Lincoln. 


\title{
Analysis of Aerial Photography for Nitrogen Stress within Corn Fields
}

\author{
Tracy M. Blackmer,* James S. Schepers, Gary E. Varvel, and George E. Meyer
}

\begin{abstract}
Spatial variability of soil parameters within fields complicates $\mathbf{N}$ fertilizer recommendations for corn (Zea mays L.) production. Thus, the ability to identify differences in crop $\mathbf{N}$ status within corn fields could lead to efficiencies in $\mathbf{N}$ fertilizer application and decreased ground water pollution. In this study, we digitized aerial color photographic transparencies using an eight-bit scheme to generate digital counts for the red, green, and blue primary colors in the photographs at the $\mathbf{R 5}$ growth stage and related them to grain yield. Digital count responses were relative to the $\mathbf{N}$ treatment in which grain yield plateaued. Experiments were conducted in 1992 and 1993 for four irrigated corn hybrids with five $\mathbf{N}$ rates on a 6-ha field near Shelton, $N E$. Red and green digital counts relative to those for the high $\mathbf{N}$ treatment provided better prediction of yield response than relative blue counts in both years. In 1993, black-and-white photographs taken with a filter centered around $536 \mathrm{~nm}$ also predicted yield response to $\mathrm{N}$ well $\left(r^{2}=0.93\right)$. These findings permit the use of low cost aerial photographs to characterize variability in crop $\mathrm{N}$ status throughout entire fields.
\end{abstract}

$\mathrm{V}$ ARIOUS TYPES OF PLANT STRESS have been identified using remote sensing techniques (Jackson, 1986). One of the first studies was conducted by Colwell (1956) using aerial photography (one form of remote sensing) to look at the prevalence of disease in wheat. Aerial photography has also been used to detect insect damage and nutrient and water deficiencies (Wildman, 1982). Because of the number of different stresses detectable photographically, specific stresses need to be verified by ground observations (truthing) or by inclusion of known reference conditions within the photograph.

Quantitative interpretation of aerial photographs is aided by digitizing the image and computerized processing of the resulting digital counts. Digitized photography has been used, for example, to evaluate the ground cover of plant canopies (Gerbermann et al., 1976; Thomas et al., 1988) and crop residues on soil (Meyer et al., 1988). Aerial photography is a way to cover large areas quickly and produce images that are spatially uniform in lighting and viewing angles. Recently, low cost digital color imaging methods have become readily available.

The green color of plant canopies is most frequently associated with leaf chlorophyll content, which is positively correlated with $\mathrm{N}$ concentration for many agricultural plants (Wolfe et al., 1988). The chlorophyll content, in turn, affects the amount of light absorbed or reflected (Al-Abbas et al., 1974; Thomas and Gausman, 1977; Maas and Dunlap, 1989). Light reflectance in the visible wavelengths $(400-700 \mathrm{~nm})$ increases with $\mathrm{N}$ deficiency (Walburg et al., 1982; Hinzman et al., 1986; Takebe et

T.M. Blackmer, J.S. Schepers, and G.E. Varvel, USDA-ARS and Dep. of Agronomy, and G.E. Meyer, Dep. of Biological Systems Engineering, Univ. of Nebraska, Lincoln, NE 68583. Joint contribution of the USDA-ARS and the Neb. Agric. Res. Div., Journal Series no. 11038. Received 7 June 1994. *Corresponding author (Email: tblackme@unlinfo.unl.edu ).

Published in Agron. J. 88:729-733 (1996). al., 1990; Blackmer et al., 1994), because chlorophyll is an efficient absorber of visible light. Although reflectance from a corn canopy depends on many factors, including incident lighting, background, and physiological condition of the crop (Colwell, 1974), $\mathrm{N}$ deficiencies can be detected by calibrating photographic responses within fields against responses from areas measured as nonlimiting in $\mathbf{N}$.

It is not practical for producers to establish a series of $\mathbf{N}$ rate areas in a field for each corn hybrid for calibration purposes. Schepers et al. (1992) proposed the use of areas within fields that receive ample or excess fertilizer $\mathrm{N}$ as reference targets when using chlorophyll meters to monitor crop $\mathrm{N}$ status. They found that chlorophyll meter readings (a ratio of light transmittance at 650 and $940 \mathrm{~nm}$ ) first increased with fertilizer $N$ application rates and then plateaued as $\mathrm{N}$ became ample. Apparently, as $\mathrm{N}$ rates increased, other nutrients and/or metabolic processes became limiting.

The chlorophyll content corresponding to luxury consumption of $\mathbf{N}$ depends on development stage (Blackmer and Schepers, 1995). Even though there can be luxury consumption of $\mathrm{N}$, leaf chlorophyll content reaches an upper limit. This upper limit changes during the growing season with the age of the leaf tissue. Once $\mathrm{N}$ supply to corn is adequate, the reflectance of corn canopies changes little as the $\mathrm{N}$ supply increases further (Blackmer et al., 1996). The use of a within-field reference also permits the separation of $\mathrm{N}$ stress from other stresses that may also be detected photographically.

Variable rate fertilizer applicators, now available commercially, have created the need for better methods of characterizing spatial patterns of $\mathrm{N}$ availability within fields. Our objectives were to test color aerial photography for measuring the variability of crop $\mathrm{N}$ deficiency and to relate color responses as detected in transparencies to differences in $\mathbf{N}$ status within fields.

\section{MATERIALS AND METHODS}

Studies were conducted in 1992 and 1993 on continuous corn $\mathrm{N}$ response trials with four hybrids on irrigated plots at the Management Systems Evaluation Area (MSEA) project near Shelton, NE. Corn was planted in late April and early May in plots of eight rows (91-cm row spacing) by $15.2 \mathrm{~m}$. The corn was fertilized at planting with $\mathrm{NH}_{4} \mathrm{NO}_{3}$ broadcast at rates of $0,40,80,120$ and with $160 \mathrm{~kg} \mathrm{~N} \mathrm{ha}^{-1}$ in 1992 and $0,50,100,150$, and $200 \mathrm{~kg} \mathrm{~N}^{-1}$ in 1993 . Pioneer brand $3162,3379,3394$, and 3417 hybrids were planted at approximately 65000 seeds ha $^{-1}$ in four replications. The experimental design was a split-plot randomized complete block with hybrid as the whole plot and $\mathrm{N}$ treatment as the subplot.

Aerial photographs (using $35-\mathrm{mm}$ film) were taken in late August in both 1992 and 1993 from a height of approximately $1000 \mathrm{~m}$ under similar conditions and camera settings. In 1992, Kodak Gold 400 color film was used to collect images; in 
1993, Kodak Gold 200 was used.' In 1993, images were also taken with a Corion bandpass filter with a central wavelength of $536 \mathrm{~nm}$ and bandwidth of $25 \mathrm{~nm}$, on Kodak TMAX ASA 3200 black-and-white film. Photographic analysis for the color film used a negative in 1993 and a positive slide of a color photograph in 1992. In 1993, the negative was used for the black-and-white image. Slides and negatives were digitized using a slide scanner (Nikon LS 3500) and the software package Photostyler by Aldus under Windows NT version 3.51 on a 486-66 $\mathrm{MHz}$ microcomputer. The settings were changed to make the tones in the digitized image similar to those in the color photograph. With these adjustments, comparisons were limited to within a given photograph only. Each digitized image was analyzed using the Media Cybernetics Image Pro Plus software package. The size of the image was scanned to represent approximately $400 \mathrm{~m}$ by $300 \mathrm{~m}$, with a resolution of 1176 pixels per plot (i.e., with a pixel representing $0.094 \mathrm{~m}^{2}$ of ground area).

The emulsions of these films respond only to light with wavelengths in the visible region of the electromagnetic spectrum. The Nikon scanner provided a VGA image with 24-bit true color ( 8 bits red, 8 bits green, and 8 bits blue). Each binary primary color value represented raw RGB digital counts within the range from 0 to 255 . Color coordinates are directly proportional to the total reflected light from the viewed scene. Normalized coordinates are derived by dividing the digital counts for each primary color by the sum of the digital counts for the red, green, and blue (Jain, 1989).

Digital counts for all pixels within each $\mathrm{N}$ rate plot were averaged for each of the three primary colors. Digital counts for a given primary color divided by the mean digital count of the reference $\mathbf{N}$ rate plot (highest three $\mathrm{N}$ rates in 1992 and the highest $\mathrm{N}$ rate in 1993) within each hybrid are the relative digital counts for a given $\mathbf{N}$ rate plot. The black-and-white images suffered from vignetting; i.e., they were darker at the

\footnotetext{
'Mention of a trade name or proprietary product does not indicate endorsement by the USDA and does not imply its approval to the exclusion of other products that may also be suitable.
}

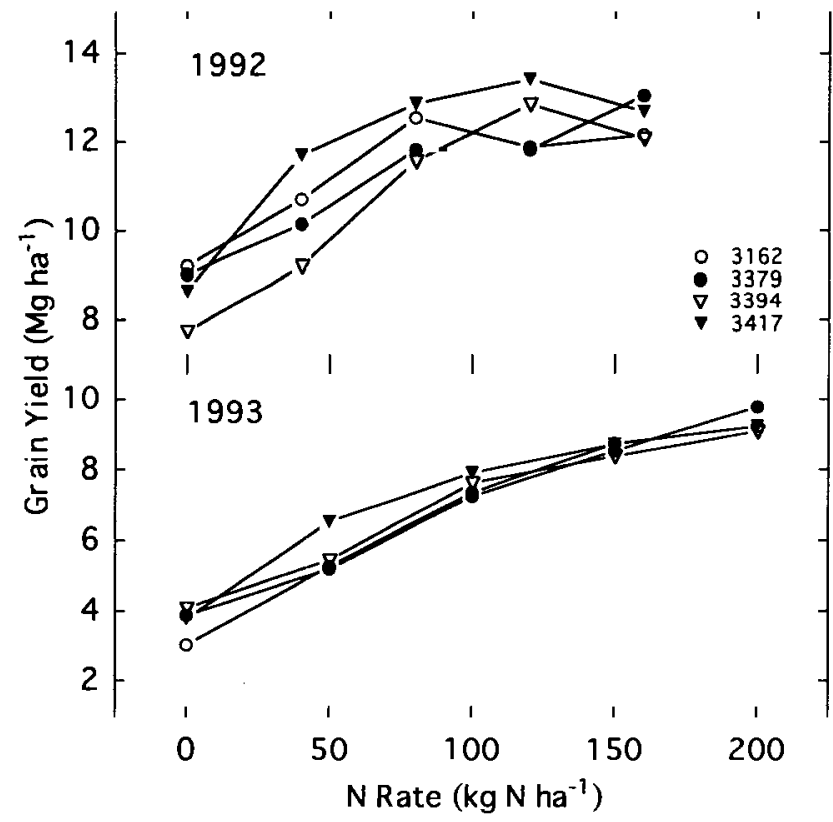

Fig. 1. Grain yields for four Pioneer brand corn hybrids to which five $\mathbf{N}$ rates were applied in 1992 and 1993. edges than at the center. Consequently, assuming the digital counts from the bare soil were constant throughout the image, soil in the alleyways adjacent to each plot was used to generate a quadratic equation that described digital counts as a function of field position or location across the entire image. Digital counts from bare soil were assumed to be constant in the image. Based on this assumption, the change in values calculated from the quadratic equation was then subtracted from the digital counts measured from each vegetative plot.

Grain yields were determined using a plot combine to harvest three rows from each plot ( $45.6 \mathrm{~m}$ of row) in 1992 . Because of a windstorm in 1993 , grain from $3.0 \mathrm{~m}$ of a single row was hand harvested. Yield data were adjusted to $155 \mathrm{~g} \mathrm{~kg}^{-1}$ moisture. Statistical analyses were conducted separately for each year because of the difference in $\mathrm{N}$ fertilization rates. Analyses of variance and linear regression analyses were used to determine significance and predictability of relationships. All relationships were tested as linear functions. Relative grain yields were calculated by dividing grain yields by the mean yield of the three highest $\mathrm{N}$ rates (the $\mathrm{N}$ response plateau) in 1992 , and by the yield of the highest $N$ rate in 1993, because no yield response plateau was observed.

\section{RESULTS AND DISCUSSION}

Grain yield in 1992 and 1993 responded positively to applications of $\mathbf{N}$ fertilizer (Fig. 1). Maximum yields were obtained with $80 \mathrm{~kg} \mathrm{~N} \mathrm{ha}^{-1}$ in 1992 , because of high residual $\mathrm{N}$ in the soil. In contrast, in 1993 maximum yields may not have been obtained with an application of $200 \mathrm{~kg} \mathrm{~N} \mathrm{ha}^{-1}$. The greater $\mathrm{N}$ requirement in 1993 was caused in part by losses of fertilizer $\mathrm{N}$ resulting from $750 \mathrm{~mm}$ precipitation within the growing season, compared with the long-term average of $320 \mathrm{~mm}$. Stalk breakage caused by a strong wind on 8 July, shortly before tasseling, may have also contributed to lower grain yields in 1993. Plant wind damage (or green-snap) generally increased with fertilizer $\mathbf{N}$ rate. Some hybrids were more susceptible to breakage at this stage of growth than others. Reduction in plant population because of the wind ranged from 5 to $30 \%$ within plots. Because of the unpredictable and irregular pattern of stalk breakage, $3 \mathrm{~m}$ long row segments hand harvested in 1993 were selected that had about the same amount of storm damage.

\section{Color Film}

The relationship between mean nonnormalized (raw) digital counts by primary color and grain yield for each hybrid was good (Table 1). Because the difference in $\mathrm{N}$ applied was the only treatment affecting yield for each

Table 1. Coefficient of determination by year between digital counts for green, red, and blue color components of Kodak Gold film and relative grain yields produced by four Pioneer brand corn hybrids fertilized at five $\mathbf{N}$ rates for 1992 and 1993.

\begin{tabular}{lccccccc} 
& \multicolumn{5}{c}{$r^{2}$ for digital counts } \\
\cline { 2 - 4 } \cline { 5 - 7 } Hybrid & Green & Blue & Red & & Green & Blue & Red \\
\cline { 2 - 4 } 31692 & 0.64 & 0.47 & 0.65 & & 0.92 & 0.91 & 0.96 \\
3379 & 0.91 & 0.81 & 0.90 & & 0.99 & 0.97 & 0.99 \\
3394 & 0.97 & 0.94 & 0.97 & & 0.90 & 0.86 & 0.91 \\
3417 & 0.83 & 0.83 & 0.85 & & 0.94 & 0.88 & 0.95 \\
\hline
\end{tabular}


hybrid (Fig. 1), it appears that digital counts can be used to detect yield reductions resulting from $\mathrm{N}$ stress (Table 1). The poor relationship in 1992 between average digital count and grain yield for Pioneer brand hybrid 3162 was attributed to an early frost that reduced the grain-filling period. Hybrid 3162 requires the longest growing season of the four hybrids.

Relationships between relative grain yields and raw digital counts were significant (Table 1) for all three color separations (Fig. 2). Coefficient of determination $\left(r^{2}\right)$ calculations (Table 1) gave better relationships for the green and red bands than for the blue band.

Digital counts followed similar trends to grain yield response for both years, but yield differences were greater in 1992 (Fig. 1) and the digital count range was greater for 1992 than for 1993 (Fig. 2). Caution should be exercised when interpreting these data, because differences in digital counts were influenced by background lighting and photographic and digitizing techniques. Ground cover by the corn was also more complete in 1992 than 1993. There was a significant $(P<0.05)$ hybrid effect for the green and red digital counts in 1992 and for the blue and green digital counts in 1993. These differences would not be a problem if an image captured an entire management area containing a single hybrid. In such a case, the cover and hybrid differences would not complicate the interpretation of spatially distributed $\mathrm{N}$ stress.

Hybrids having the same $\mathrm{N}$ status could differ in digital counts because of differences in the light interaction with the corn canopy caused by differences in pigmentation or canopy architecture (e.g., leaf orientation, leaf area, and leaf thickness). Differences among hybrids can be minimized by calculating a relative color coordinate (rel- ative digital counts) similar to the way relative grain yields are calculated (Fig. 3). Comparison of the results shown in Fig. 2 and 3 shows that use of relative digital counts did reduce the variation among hybrids. Normalizing (comparing values to a non-N-limiting fertilized reference) both grain yield and digital counts suggests that it should be possible to evaluate management areas with more than one hybrid. Differences shown in relative grain yield versus digital count data between years (Fig. 3 ) result from the differences in grain yields and digital count ranges within years.

The linear relationships observed in Fig. 3 for 1992 and 1993 indicated that relative digital counts do not increase with increasing degrees of excess $\mathrm{N}$ availability (i.e., luxury consumption). The inability to distinguish between degrees of excess $\mathrm{N}$ availability eliminates the need to accurately predict the exact amount of $\mathrm{N}$ required for optimal production in the reference areas as long as nonlimiting rates are applied and crop cover is sufficient (i.e., little soil background is sensed). The practical value of the relative digital counts increases with any improvement in yield response predictability. Spectral measurements in the appropriate wavelengths also increase the sensitivity of the spectral observations.

\section{Black-and-White Film}

Photographic images are sensitive to the visible spectral range, from about 450 to $700 \mathrm{~nm}$, depending on the optical bandpass filters used. A filter that restricted film response to a narrow bandwidth of reflected light around $540 \mathrm{~nm}$ was used in 1993, to determine if narrowing the measured spectrum would provide a better prediction of corn yield. When only a single narrow bandwidth is

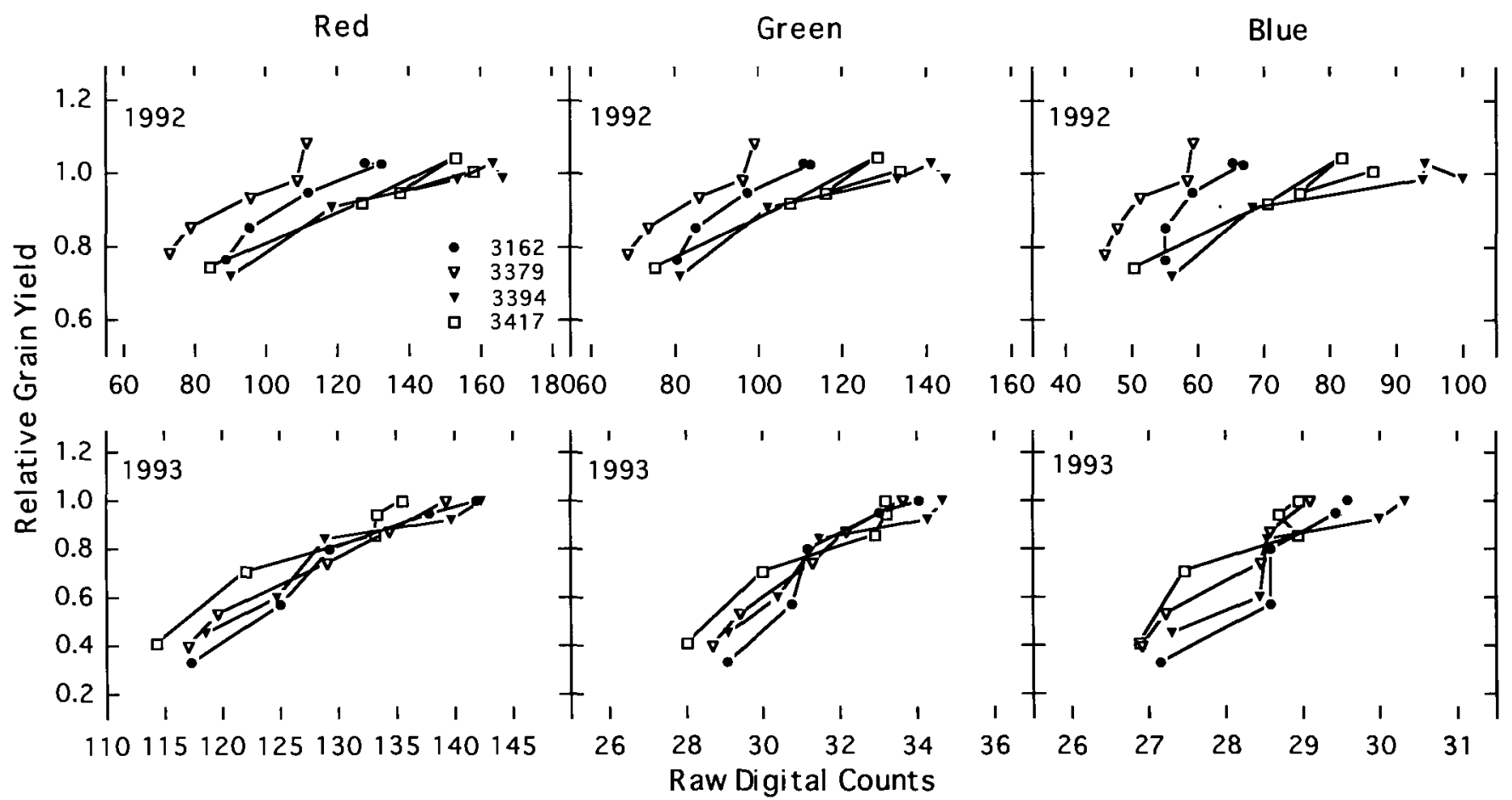

Fig. 2. Relationships between relative grain yield and raw digital counts of red, blue, and green color responses of Kodak Gold film for four Pioneer brand corn hybrids and five $N$ rates in 1992 and 1993. 


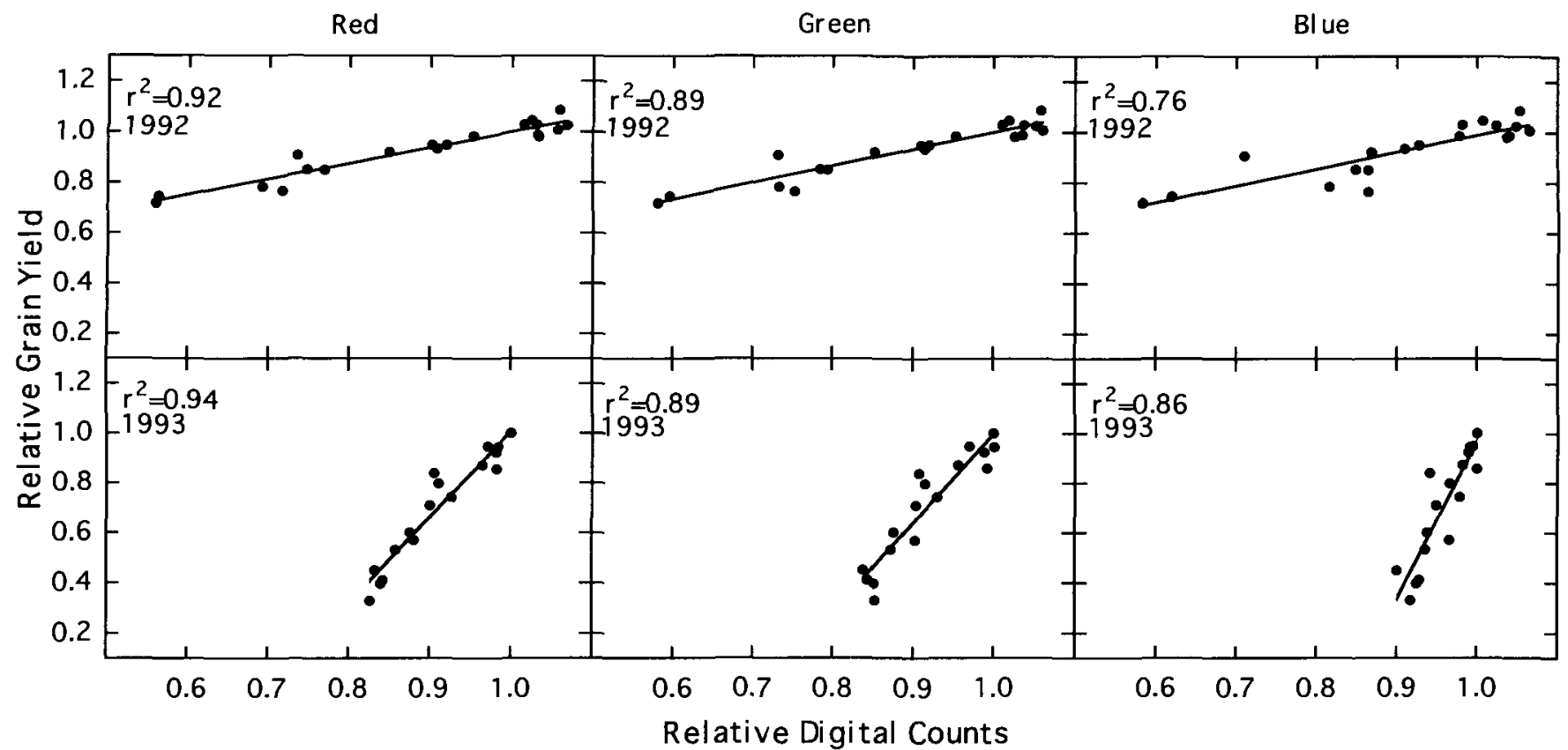

Fig. 3. Relationships between relative grain yield and relative digital counts of red, blue, and green color responses of Kodak Gold film across four corn hybrids and five $N$ rates in 1992 and 1993.

measured, black and white is the only appropriate film to use.

Digital counts from the black-and-white negative transparencies, using white light in the digitizing beam, sensed the film exposure responses (Fig. 4a) in the bandpass filter interval chosen $(536 \pm 12.5 \mathrm{~nm})$. The black-andwhite film was more optimally exposed to sense the $\mathrm{N}$ stress than were the color films. However, vignetting in the black-and-white negatives caused problems with image interpretation. After making the appropriate corrections (see Materials and Methods), the predictability (coefficient of determination) of grain yield response

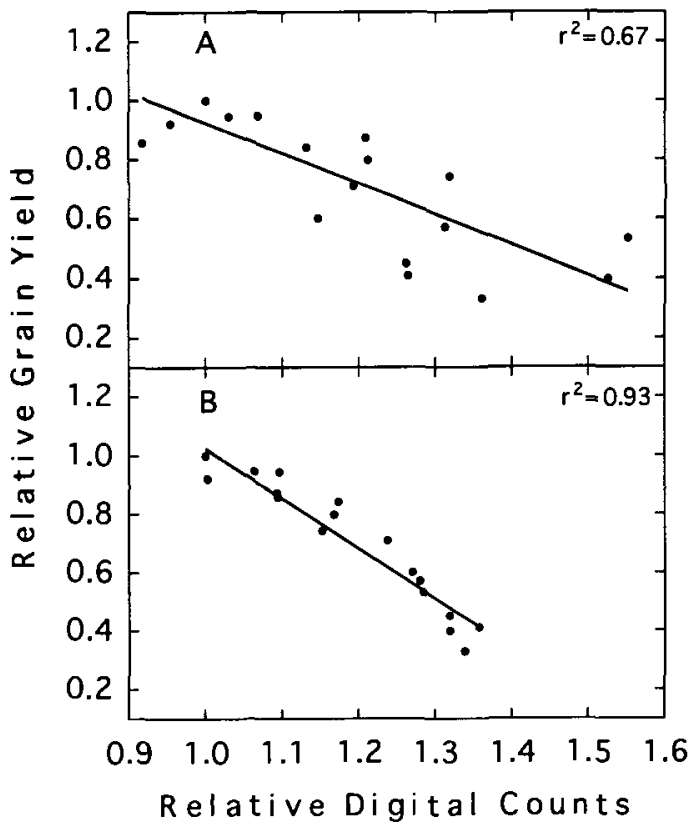

Fig. 4. Relationships between relative grain yield and relative digital counts for (a) raw data and (b) data corrected for vignetting, across four corn hybrids and five $\mathrm{N}$ rates. across all four hybrids increased from 0.67 to 0.93 . Relative gray-scale values corrected for distortion (Fig. 4b) provided a similar relationship to those obtained from color photographic images (Fig. 3). The opposite direction of the slope in Fig. 4 compared with Fig. 2 and 3 is a result of using a different type of film (black and white, rather than color).

\section{CONCLUSION}

Photographic transparencies provided detection of $\mathrm{N}$ deficiency of irrigated corn. The red relative digital counts provided better $\mathbf{N}$ deficiency detection than the green or blue relative digital counts. Relative digital counts for black-and-white positive film exposed with a narrow band filter centered on $536 \mathrm{~nm}$ predicted grain yields well when corrected for distortion. However, relative digital counts and relative yields could not be pooled across years, because the grain yields and methods to obtain digital counts differed in 1992 and 1993. Pooling digitized data from aerial photographs across years or even across sampling dates within a growing season is not necessary if the anticipated use of this technique is a point-in-time assessment of crop $\mathrm{N}$ status. These results suggest that qualitative assessments of within-field variability can be made using photographic techniques and that such techniques can identify portions of a field that are $\mathrm{N}$ deficient compared with the rest of the field. An aerial photograph has the advantage of being able to detect stress within any portion of a field. If responses are strong enough, a photograph can also identify variability caused by equipment and management.

\section{REFERENCES}

Al-Abbas, A.H., R. Barr, J.D. Hall, F.L. Crane, and M.F. Baumgardner. 1974. Spectra of normal and nutrient-deficient maize leaves. Agron. J. 66: 16-20.

Blackmer, T.M., and J.S. Schepers. 1995. Use of a chlorophyll meter 
to monitor $\mathrm{N}$ status and schedule fertigation of corn. J. Prod. Agric. 8:56-60.

Blackmer, T.M., J.S. Schepers, and G.E. Varvel. 1994. Light reflectance compared with other nitrogen stress measurements in corn leaves. Agron. J. 86:934-938.

Blackmer, T.M., J.S. Schepers, G.E. Varvel, and E.A. Walter-Shea. 1996. Nitrogen deficiency detection using reflected shortwave radiation from irrigated corn canopies. Agron. J. 88:1-5.

Colwell, J.E. 1974. Vegetation canopy reflectance. Remote Sens. Environ. 3:175-183.

Colwell, R.N. 1956. Determining the prevalence of certain cereal crop diseases by means of aerial photography. Hilgardia 26:22386.

Gerbermann, A.H., J.A. Cuellar, and C.L. Wiegand. 1976. Ground cover estimated from aerial photographs. Photogramm. Eng. Remote Sens. 42:551-556.

Hinzman, L.D., M.E. Bauer, and C.S.T. Daughtry. 1986. Effects of nitrogen fertilization on growth and reflectance characteristics of winter wheat. Remote Sens. Environ. 19:47-61.

Jackson, R.D. 1986. Remote sensing of biotic and abiotic plant stress. Annu. Rev. Phytopathol. 24:265-87.

Jain, A.K. 1989. Fundamentals of digital image processing. Prentice Hall, Englewood Cliffs, NJ.

Maas, S.J., and J.R. Dunlap. 1989. Reflectance, transmittance, and absorptance of light by normal, etiolated, and albino corn leaves. Agron. J. 81:105-110.

Meyer, G.E., A. Stepanek, D.P. Shelton, and E.C. Dickey, 1988.
Electronic image analysis of crop residue cover on soil. Trans. ASAE 31:968-973.

Schepers, J.S., T.M. Blackmer, and D.D. Francis. 1992. Predicting $\mathrm{N}$ fertilizer needs for corn in humid regions: using chlorophyll meters. p. 105-114. In B.R. Bock and K.R. Kelley (ed.) Predicting $\mathrm{N}$ fertilizer needs for corn in humid regions. Bull. Y-226. Natl. Fertilizer and Environmental Res. Ctr., Muscle Shoals, AL.

Takebe, M., T. Yoneyama, K. Inada, and T. Murakami. 1990. Spectral reflectance of rice canopy for estimating crop nitrogen status. Plant Soil 122:295-297.

Thomas, J.R., and H.W. Gausman. 1977. Leaf reflectance vs. leaf chlorophyll and carotenoid concentration for eight crops. Agron. J. 69:799-802.

Thomas, D.L., F.J.K. daSilva, and W.A. Cromer. 1988. Image processing technique for plant canopy cover evaluation. Trans. ASAE 31:428-434.

Walburg, G., M.E. Bauer, C.S.T. Daughtry, and T.L. Housley. 1982. Effects of nitrogen nutrition on the growth, yield, and refiectance characteristics of corn canopies. Agron. J. 74:677-683.

Wildman, W.E. 1982. Detection and management of soil, irrigation, and drainage problems. p. 387-401. In C.J. Johannsen and J.L. Sanders (ed.) Remote sensing for resource management. Soil Conserv. Soc. Am., Ankeny, IA.

Wolfe, D.W., D.W. Henderson, T.C. Hsiao, and A. Alvino. 1988. Interactive water and nitrogen effects on senescence of maize: II. Photosynthetic decline and longevity of individual leaves. Agron. J. 80:865-870. 